\title{
On the Origins of Analytic Philosophy ${ }^{1}$
}

\author{
Barry Smith
}

Review essay on Michael Dummett, Ursprünge der analytischen Philosophie, Frankfurt a. M.: Suhrkamp, 1988 from Grazer Philosophische Studien, 34 (1989), 153-173.

For some time now, historians of philosophy have been gradually coming to terms with the idea that post-Kantian philosophy in the German-speaking world ought properly to be divided into two separate traditions which, for want of a better alternative, we might refer to these as the German and Austrian traditions, respectively. The main line of the first consists in a list of personages beginning with Kant, Fichte, Hegel, Schelling, Ulrici, Cohen, and ending with Heidegger, Adorno and Bloch. The main line of the second may be picked out similarly by means of a list beginning with Bolzano, Brentano, Meinong, Twardowski, the early Husserl, and ending with Wittgenstein, Neurath and Gödel.

Austrian philosophy is characterised by a concentration on problems of logic, language and ontology. It is a philosophy of detail, a philosophy 'from below', often dealing with examples drawn from extra-philosophical sciences. It is characterised by a simplicity and straightforwardness of style that is in marked contrast to what (at least from the usual Anglo-Saxon perspective) seems like an oratorical and

1. What follows has benefitted from suggestions of Ernie Lepore, Kevin Mulligan, Karl Schuhmann, Peter Simons and especially Johannes Brandl. 
obfuscatory verbigeration on the part of philosophers of the German sort. And it is marked further by a sympathy towards and in many cases a rootedness in British empiricist philosophy. Moreover, because the Kantian revolution was not accepted in Austria, this philosophy is marked further by a special relation to realism, understood both in an ontological and in an epistemological sense.

German philosophy, on the other hand, has remained faithful to Kant, in the sense that it has been centred largely around concerns deriving from epistemology and ethics. It is in almost all cases a philosophy 'from above', in which definitions, arguments and examples play a minor role. It is marked by historicism, idealism and transcendentalism, and by an almost total neglect of the instruments of modern logic.

As should by now be clear, it is the Austrian tradition that has contributed most to what has come to be accepted as the mainstream of philosophical thinking. For while there are of course German thinkers who have made crucial contributions to the development of analytic philosophy - one thinks above all of Frege, but mention might also be made of Weyl, Gentzen, Schlick, Carnap and Reichenbach - such thinkers were outsiders, and in fact a number of them, as in the case of Brentano himself, found their philosophical home in Vienna.

When we examine in detail the influence of the Austrian line, we encounter a whole series of hitherto unsuspected links to the characteristic concerns of more recent philosophy of the analytic sort. Think, for instance, of the role of Brentano's disciple Twardowski in inspiring his students in Lemberg to undertake investigations of the nature of the proposition and of judgment, investigations which led not merely to technical discoveries in the field of propositional logic but also, ultimately, to Tarski's work on the semantic conception of truth. Consider Lukasiewicz's work on many-valued logic, inspired in part by Meinong, with whom Lukasiewicz had studied in Graz. 
Consider the work of Husserl's student Adolf Reinach who, in 1913, invented a version of the theory of speech acts subsequently rediscovered in Oxford in the '50s. Or think of Brentano's reism and Sprachkritik, or Lesniewski's anticipation of work by Leonard, Goodman and Quine on the formal foundations of nominalist philosophy, or Ernst Mally's anticipation of what later came to be called 'deontic logic'.

Analytic philosophers themselves have until recently been reluctant to pursue historical investigations into these Central European roots of their own philosophical tradition. The most recent book by Michael Dummett, however, a brilliantly provocative series of lectures originally presented in Bologna under the title Origins of Analytic Philosophy, ${ }^{2}$ shows how fruitful such investigations can be, not only as a means of coming to see familiar philosophical problems in a new light, but also as a means of clarifying what, precisely, 'analytic philosophy' might mean. As Dummett points out, the newly fashionable habit of referring to analytic philosophy as 'AngloAmerican' leads to a 'grave historical distortion'. If, he says, we take into account the historical context in which analytic philosophy developed, then such philosophy 'could at least as well be called "Anglo-Austrian"' (p. 7).

As Dummett notes, it was a plurality of tendencies in Central European thought that contributed in the 20th century to the development of analytic philosophy. Dummett himself, however, concentrates principally on just one aspect of this historical complex, namely on the relationship between the theories of meaning and

2. Michael Dummett, Ursprünge der analytischen Philosophie, translated by Joachim Schulte, Frankfurt a. M.: Suhrkamp, 1988, 200 pp. All references are to this work unless otherwise indicated. The volume includes as an appendix the record of a conversation between Schulte and Dummett dealing especially with more recent developments in analytic philosophy. The main text of Dummett's lectures has appeared in English in the journal Lingua e stile, 23 (1988), 3-49 and 171-210. 
reference developed by Frege and by Husserl in the years around the turn of the century. How could it come about that Frege, the grandfather of analytic philosophy, and Husserl, the founder of phenomenology, could have shared so much at the beginning of their careers, and yet have given rise to such divergent ways of doing philosophy?

The present essay is principally devoted to this specific issue and to Dummett's treatment thereof, which seems to mark an important new beginning in what one might call the historical self-consciousness of the analytic movement. For the sake of completeness however it should be pointed out that Dummett's book provides also a number of interesting clarifications of Dummett's own earlier views, above all on the question as to how a theory of meaning for a natural language ought properly to be conceived. The work contains criticisms of Wittgenstein and Davidson along lines that will be familiar from Dummett's other writings; and as is to be expected, the work contains also a series of attempts on Dummett's part to extrapolate Frege's

original formulations in the direction of a more sophisticated but still recognisably Fregean position. Since, however, our concerns here are directed primarily towards historical ground-clearing, this sophisticated Frege will generally be neglected in what follows.

\section{Psychologism}

We might conceive Frege's and Husserl's theories as competing strategies in relation to two problems, both of which became acute around the turn of the century: the problem of psychologism on the one hand, and the problem of intentionality on the other.

For our present purposes we can regard psychologism as a view which assumes that logic takes its subject-matter from the psychology of thinking. A doctrine of this sort has a number of advantages. If thoughts or propositions are (as the psychologist supposes) internal to 
the mind, then it is very easy to see how they play a role in our cognitive activities and how we come to 'grasp' them. The psychologist has an easy time also in explaining how logic should be applicable to these cognitive activities as they actually occur. Yet these advantages are, unfortunately, outweighed by the relativistic consequences which psychologism brings in its wake. Above all, if thoughts are internal to the mind, it becomes difficult to see how they could be communicated and how they could become bound together to form what we call scientific theories. For these and other reasons Bolzano, Frege, Meinong and Husserl were led to the view that thoughts cannot, like images and dreams, be immanent to the mind of the cognising subject. A thought, as Dummett puts it, 'is common to all, as being accessible to all.' (p. 33)

Bolzano, Frege, Meinong and Husserl went further than this, however, in holding that thoughts and their constituents are not merely (1) external to the mind. They are also (2) external to the world of what happens and is the case. And they are (3) objective, in the sense that they do not depend for their existence on our grasping of them. Moreover, they are (4) non-actual, in the sense that they play no role in causal relations. Frege, in particular, embraced also a view of thoughts as (5) objects, i.e. as entities comparable in form to tables, chairs, people and other objects of a more humdrum sort. We might use the term 'full platonism' for the view of thoughts which accepts all five features, and talk of 'full psychologism' in relation to the diametrically opposite view. Clearly, a number of combinations are possible between these two extremes. Thus, among the heirs of Brentano, both Meinong and Husserl accepted (1) to (4) but denied (5). Anton Marty developed a view of judgment-contents or Urteilsinhalte as mind-transcendent but non-objective (i.e. as satisfying only (1) and (4)). And Carl Stumpf, who was, like Marty and Frege, a student of Lotze in Göttingen, introduced the term 'Sachverhalt' into Austrian philosophy to signify judgment-contents 
conceived as entities that are non-actual but immanent to the mind, so that Sachverhalte, as Stumpf conceives them, satisfy only (4).

It would be interesting to establish from an ontological point of view what precisely are the options available here. For the moment, however, we shall assume that Dummett is correct when he argues that

[t]he importance of the denial of the mental character of thoughts, common to Bolzano, Frege, Meinong and Husserl, did not lie in the philosophical mythology to which it gave rise

- Frege's myth of the 'third realm' or Husserl's of 'ideal being'. It lay, rather, in the non-psychological direction given to the analysis of concepts and of propositions. (p. 36)

It is this new direction which made possible the birth of modern logic - and as already mentioned, it was not least among Brentano's heirs in Poland that there evolved the new techniques of propositional logic, techniques for manipulating propositions newly freed from their bondage to psychology.

\section{Grasping at Thoughts}

When once psychologism is rejected, and thoughts are banished from the psyche, then the problems which psychologism found it so easy to resolve must be squarely faced. How, if thoughts or senses are external to the mind, do they relate to our cognitive activities? How, in Fregean terminology, does it come about that we are able to grasp them? And how does logic come to be applicable to our actual thinkings and inferrings? Frege seeks to solve these problems, in effect, by assigning to language the job of mediating between cognitive events on the one hand and thoughts and their constituent meanings on the other. Unfortunately however he does not specify how this mediation should be effected. Thus he does not tell us how, in using language, we should be related to meanings: 
For Frege an expression simply has a sense; one who uses it does not need to bear its sense in mind throughout the process of employing it. (p. 18)

Moreover, Frege does not tell us how thoughts themselves should be related to the corresponding bits of language. For the platonist, thoughts and their constituents look after themselves, so that the fact that there is any link at all between thoughts and the sentences which express them comes to seem like some sort of magic. Indeed Frege defends the view (shared also by Bolzano) that it does not belong to the essence of thoughts to be brought to expression in language at all. Frege sees no contradiction in the assumption of a being who could grasp thoughts directly, without linguistic clothing, even if for us humans it is necessary that a thought of which we are conscious enters into our consciousness always with some sentence or other. All of this means, however, that we cannot derive from Frege's own writings a clear account of what it is to grasp a sense, nor of how it is determined which sense is bound up with which expression. The precise mental processes that consciously take place in one who uses the expression are for Frege irrelevant.

Frege's successors sought ways of securing a link between meaning, language and use by conceiving language itself as that which serves to fill the gaps. Thus Wittgenstein might be said to have conceived both mental acts and objective meanings as dependent upon or as secondary to language itself: they are different sides or aspects of that complex social and institutional whole which is language as used. Dummett, too, seems to embrace a dependence of this sort. He is, however, fully aware of the fact that it is possible to advance claims on behalf of another means of filling in these gaps - one which would award the central role not to language but to our mental acts and to their underlying dispositions. And because it is Husserl who has done most to make sense out of this alternative approach - against the background of a non-psychologistic theory of meaning that is in 
some respects very similar to that of Frege - Dummett seeks here to provide arguments against what he takes to be this Husserlian alternative.

\section{Intentionality, or: How to Misread Brentano}

The second problem at the core of the divergence between Frege and Husserl is the problem of intentionality. A central chapter of Dummett's book is entitled "Brentano's Legacy" and is a sketch of how this problem arose and was bequeathed by Brentano to his successors. Brentano's 'most familiar positive thesis', Dummett tells us - the thesis that acts of consciousness are characterised by their intentionality - consists in the claim that all such acts are 'directed towards external objects'. The object of a mental act is, for Brentano, 'external in the full sense of being part of the objective world independent of the subject, rather than a constituent of his consciousness.' (p. 39)

Unfortunately Dummett quite simply misunderstands Brentano here, in a way which owes much to a series of attempts on the part of some of Brentano's admirers to make his views seem more straightforward and commonsensical than the texts would properly permit. ${ }^{3}$ Certainly in the famous 'intentionality passage' in the Psychology from an Empirical Standpoint Brentano's views on this matter are not unambiguously expressed. Yet Brentano himself appends a footnote to this passage in which he makes abundantly clear that for him the intentionality relation holds between an act and an

3. The passage quoted by Dummett on p. 40 to support his reading of Brentano, a passage he takes from an essay by F $\phi 1$ lesdal, appears in Brentano's text in a context which makes it irrelevant to the issue in hand. (See F $\phi l l e s d a l ' s$ paper "Brentano and Husserl on Intentional Objects and Perception", in H. L. Dreyfus, ed., Husserl, Intentionality and Cognitive Science, Cambridge, Mass.: MIT Press, 1982, and compare Psychology from an Empirical Standpoint, London: Routledge and Kegan Paul, 1973, p. 385.) 
object immanent to the mind. ${ }^{4}$ This same thesis is to be found also in Brentano's more detailed formulations of his views on this matter in the Deskriptive Psychologie. ${ }^{5}$ And even in his later, reistic phase, when Brentano no longer conceived objects of thought as immanent to the mind, he still goes out of his way to emphasise that 'things' or 'ens reale' as he understands them are not at all to be identified with the sorts of external objects which are normally supposed to people the world and to be the targets of our acts (objects in relation to which Brentano maintained a consistently sceptical stance).

It cannot, however, be denied that Brentano's ontology of mind inspired his students to develop a range of alternative accounts of how it is that acts and objects, including putative external objects, are related together. The problem of intentionality to which they can be seen to have addressed themselves, a problem that is still very much alive in philosophy today, may be formulated as follows: how are we to understand the directedness of our acts, their capacity to point beyond themselves to objects, given that not all our acts are veridical (that they are not all such as to have an object in the strict sense).

For Frege, as for Lotze, all directedness to objects is held to be achieved via the objective reference of our thoughts or senses. ${ }^{6}$ Wherever there is sense or meaning there is also a directedness to objects, and wherever there is directedness to objects there is also

4. Brentano points out that 'Aristotle himself had spoken of this mental in-existence' and he goes on to elaborate Aristotle's theory according to which 'the object which is thought is in the thinking intellect.' See Psychology from an Empirical Standpoint, pp. 88f.

5. Edited by R. M. Chisholm and W. Baumgartner, Hamburg: Meiner, 1982, esp. 10-27. Here Brentano explicitly contrasts 'parts of the soul' in the strict or literal and in the modifying sense, and assigns what he calls 'immanent objects' to the former class.

6. This holds even for that sort of directedness to objects which is involved in sensory perception, since on Frege's view the way in which an object is given to us is always a sense. See Dummett's ch. 9, on Frege's theory of perception. 
sense or meaning. The realm of thoughts and senses is, as Frege conceives it, the realm of modes of being given of entities of different sorts, and because thoughts and senses are accessible to us only via language, it follows that such modes of being given are for us always also modes of determining the object-relatedness of some corresponding expression. The sense of a common or garden singular term is, unsurprisingly, the way of determining its common or garden referent. But what of the senses of other sorts of expressions? Here Frege, familiarly, awards a special role to the sentence, and affirms his 'context principle' to the effect that the senses of subsentential expressions are determined by the role they play in the context of the sentence as a whole. Because, now, the referent of a sentence is held by Frege to be its truth-value, it turns out that the sense of a subsentential expression is identifiable as the contribution this expression makes to determining the truth-value of the sentence in which it occurs. But the sense of such an expression does not hereby cease to be a way of referring to some entity. In Dummett's own words, a sense is for Frege 'a step in the determination of a thought as true or false, representable as a particular means of determining a referent of the appropriate logical type.' (p. 96) It is therefore as if Frege has extended the notion of reference or object-directedness from singular terms to all significant expressions. Singular terms hereby of course keep the reference they had from the very start. In relation to expressions in other categories however - where one ought properly to speak not of reference but of something analogous thereto - Frege is led to embrace a whole menagerie of new kinds of 'saturated' and 'unsaturated' entities.

Allowing sense or meaning to determine ontology in this way is one consequence of awarding priority to language which Dummett himself might accept as unfortunate. A related consequence of Frege's account however, one which Dummett welcomes, but whose implications for ontological householding might be held to be no less 
regrettable, is that the concepts of truth and of sense or meaning come to be inextricably bound up with each other. As Dummett points out, classical 'theories of truth' such as the correspondence theory presupposed meaning as something given. The proponents of such theories

did not ask, "What, in general, renders (an utterance of) a sentence true?", but, "What, in general, renders a proposition true?". Here a proposition is what the utterance of a sentence expresses: to grasp the proposition, you must know what the sentence means. (p. 24)

Of course one should not unthinkably move from talk of sentences to talk of propositions. Dummett, though, is insisting here on a much stronger thesis to the effect that ' $[\mathrm{t}] \mathrm{ruth}$ and meaning can only be explained together, as part of a single theory.' (loc. cit.) So convinced is Dummett of the rightness of this view, that he does less than justice to the thinking of those like Husserl - as also Lesniewski, Tarski, and the early Wittgenstein - who deny it.

\section{Husserl's First Theory of Meaning}

For Frege the problem of the intentionality of acts does not arise: directedness is achieved not by acts directly but only via language (sense or meaning), and 'every use of language simply has its sense'. The problem of intentionality is replaced by the problem of grasping, a problem which Frege noticed in passing but in the solution of which he was hardly interested. For the author of Psychology from an Empirical Standpoint the problem of intentionality does not arise, since every act simply has its immanent object, and Brentano is very sceptical about the validity of our common-sense assumptions as to what these immanent objects might have as worldly correspondents. In the thought of Meinong, in contrast, the problem is trivialised, since 
Meinong denies that there are non-veridical acts in the strict sense of acts lacking objects tout court.

It seems that it was Husserl, in the Logical Investigations, who first tackled the problem of intentional directedness in a non-trivial way. In order to gauge the adequacy of Dummett's account of Husserl's views, however, we shall need to set forth the basic ingredients of his theory of part, whole and unity in whose terms these views are expressed. ${ }^{7}$ This theory is interesting above all because, unlike standard mereologies, it concerns itself not simply with relations between parts and their circumcluding wholes, but also with the different sorts of relations which can obtain among the parts within a whole. The most important such relation, for our present purposes, is that of dependence, which holds between one part and another when the former cannot as a matter of necessity exist except in a whole in which it is bound up with the latter. Such dependence, illustrated for example in the relation between a colour and its extension, may be either reciprocal or one-sided.

Those complex events we call mental acts can be sliced into dependent parts in different ways, according, as it were, as to the axis along which one chooses to slice. There are, first of all, certain sorts of constituent parts which, though not experienced as acts in their own right, are nevertheless such as to point beyond themselves in the strong sense that they are guaranteed objectual correlates. This holds above all of those act parts (called by Husserl 'Empfindungsmomente') through which sensory content is channelled in perception.

Act parts of this sort are responsible for what we might call lowgrade intentional directedness. In the normal course of mental experience, however, such act parts exist only as knitted together with other sorts of constituents (Husserl calls them 'Auffassungsmomente')

7. This theory is set out by Husserl in the third Investigation. It is applied to the structures of language in the fourth, in a way which yields results in some respects similar to those of Frege's theory of unsaturatedness. 
through which higher grades of directedness may come about. It is, crudely speaking, because the acts which result from such knitting together may fail to map any corresponding knitting together among the objectual correlates of the constituent act parts, that there arises the possibility of a non-veridicality of our acts. ${ }^{8}$ Where complex acts are veridical, however, then it is clear that they may be such as to involve a double or multiple object (may be related to objectual correlates on a number of distinct levels).

To this distinction of levels Husserl's now adds a distinction between 'empty' and 'fulfilled' intentions. Husserl saw that our acts are typically organised in different sorts of chains unfolding in time. Even though we may move back and forth in our experience from acts which are as it were supported by sensory experiences to acts in which such support is lacking, the moment of higher-level intentional directedness is nevertheless preserved on the level of the act as a whole, and this independently of whether or not there is some autonomous object to which the act might correspond.

A spectrum of possible cases can be distinguished. Most important for our purposes are:

- acts which have objects both at the level of act parts and at the level of act whole (veridical fulfilled intentions)

- acts which have objects only on the first level (non-veridical fulfilled intentions)

- acts which have objects only on the second level (veridical empty intentions)

- acts which have no objects at all (non-veridical empty intentions).

These four kinds of cases are, however, all such as to be experienced by their subjects as having objects of their own. Husserl introduces the

8. See Logical Investigations, trans. by J. N. Findlay, London: Routledge and Kegan Paul, 1970, vol. I, 309ff. 
term 'objectifying act' to cover acts which have this property. Such acts are contrasted with, say, emotions, whose object-directedness is according to Husserl taken over from other acts, as when I am angry at what I see.

Objectifying acts may involve an object-directedness at higher levels. This is above all because acts and act parts may be knitted together into those special kinds of objectifying acts we call judgments, which are experienced as being directed towards what we call Sachverhalte or states of affairs. Sachverhalte can in turn become the objects of nominal acts on still higher levels. It will however be important for what follows to note that Husserl marshals a series of arguments to the effect that the cognitive capacities presupposed by such higher level acts can be acquired only via lower lever experiences where objectual correlates are guaranteed.

Acts may stand, now, in a range of different sorts of similarity relations, reflecting the different sorts of abstractly distinguishable components (dependent parts) within the acts themselves. Thus for example acts may share a qualitative similarity on the level of act parts, or they may share a similar object-directedness on the level of the act as a whole. In the latter case Husserl talks in terms of the acts sharing a similar 'content'. Such similarity relations between act components as individuals are taken by Husserl to imply further the existence of identical species which these components instantiate (and which are thereby instantiated also, in a derivative sense, by the corresponding acts). Hence we can talk of acts having similar contents (i.e. similar immanent contents on the level of individuals); but we can also talk of acts sharing identical contents (on the level of 'ideal species').

Husserl's theory of linguistic meaning, now, is built up out of these ingredients, and it is a pity that, as we shall see, those passages in the Logical Investigations with which Dummett deals are misinterpreted by him simply because he has no appreciation of the 
nature of this special theory. Certainly in the "Prolegomena" to the Investigations, Husserl had been so concerned to distance himself from psychologism, that he disdained, like Frege, to give an explanation of how it comes about that a certain expression comes to have a certain sense. Senses were seen as constituting a realm of special objects ('ideal meanings') which can look after themselves. In the later parts of the Investigations, however, Husserl filled out his conception of meaning in a way which draws on the just-mentioned (Aristotelian) ontology of species and instantiating individuals. Here Husserl takes seriously not merely that the world of external substances is divided in different ways into hierarchies of species of different orders of generality. He holds further that the parts and moments of our mental acts, too - and he might have referred in addition to the various dispositions and capacities which underlie these - are divided into species in this way, in virtue of the similarity relations which obtain among their various components. In a bold conceptual move, Husserl now identifies linguistic meanings with certain species of this sort. And it is in this sense that we are to understand his talk of 'ideal meanings'.

To make sense of this identification we must recall, again, that acts can be sliced into parts in a variety of different ways. The results of such slicing will be in many cases such as to share with the act as a whole its character of being an event unfolding in time. The corresponding species will therefore be species of mental activity. Linguistic meanings can clearly in no way be identified with species of this sort. Some partitions of the act, however, yield constituents above all those constituents referred to above as the immanent contents of our acts - which are shorn of the event-character of the act as a whole.

It is, now, certain content-species which are identified by Husserl as the meanings of our linguistic expressions. It is accordingly no surprise that it is through reflections on language that we can most 
easily come to an understanding of what contents in general are. This epistemological fact should not, however, sanction the conclusion that contents are such as to depend for their existence on language use or on associated capacities. On the contrary, Husserl holds that language is possible only because of the brute fact that our acts and their contents (a) rest on secured access to sensible differences in reality (via the low-grade intentionality mentioned already above), and (b) manifest a range of different sorts of similarity relations, both as between one time and another and as between one subject and another.

Figuratively speaking we might characterise Husserl's theory of meaning as a 'vertical' theory, in the sense that meanings are ranged 'above' the acts which instantiate them. This instantiation comes about as it were willy nilly, in reflection of whatever are the relevant individual contents of the acts themselves. The meanings are for their part entirely inert: it is not the meaning (something ideal, a mere universal), but the act itself that is responsible for its objectdirectedness. Meanings do however serve to provide an objective subject-matter for the science of logic, and they allow us to explain communicability as consisting in the fact that the acts involved in language use on the parts of different subjects can share identical (meaning) species.

A Frege-type theory is, in contrast, a 'horizontal' theory, in the sense that it conceives meaning-entities as falling between the act (or some equivalent) and the object (if any) to which the act is referred. It is in this way that it gives rise to the linkage problem and so also to the metaphor of 'grasping'. Of course this is not to argue that Frege held that we grasp thoughts as objects. Thoughts serve rather as the means by which we come to be directed towards objects proper (including truth values). What is crucial is that these means constitute an objective realm that is interposed between our acts and the world of referents. 
The next stage in Husserl's exploitation of his theory of part, whole and species to the understanding of linguistic meaning is captured in the following passage from the first Logical Investigation: that concrete phenomenon which is an expression animated by sense divides into, on the one hand, the physical phenomenon, in which the expression constitutes itself according to its physical aspect, and, on the other hand, the acts which give it meaning and possibly also intuitive fulfilment and in which its relation to an expressed objectivity is constituted. (p. 280, translation amended and emphases removed)

Of this passage Dummett can make very little sense. He takes umbrage, above all, at Husserl's talk of 'acts which give [an expression] meaning', and concludes that

[i]t is difficult to acquit Husserl of maintaining a HumptyDumpty view of this matter: the view, namely, that an utterance assumes the meaning that it bears by an interior act of investing it with that meaning. (pp. 45f.)

He complains, in other words, about the air of arbitrariness he claims to detect in Husserl's account, as if the relation between utterance and objectifying act which lends it meaning were a matter of a more or less arbitrary association. Quite correctly, Dummett goes out of his way to criticise those act-based conceptions of meaning which conceive act and utterance as separate phenomena which have to be joined together by associative relations of one or other sort. (pp. 115ff.) A view along these lines was in fact embraced by Anton Marty. The theory defended by Husserl is however safe against such criticisms, precisely because, as the passage quoted by Dummett himself makes abundantly clear, the expression and the sense which animates it are not conceived by Husserl as separate and distinct, but as one 'concrete phenomenon' within which different sides (dependent parts or moments) can be distinguished at best only abstractly. The reader is asked to pause for a moment to reflect on this 
idea: that there are entities of special sorts, hybrids of sui generis linguistic and psychological constituents, neither of which can exist except as bound up with the other in a whole of just this sort. ${ }^{9}$

What Husserl actually means in the passage quoted can now more properly be elucidated as follows. The 'physical phenomenon' is this single concrete phenomenon conceived, abstractly, as a complex of articulated sound. To say that this utterance is 'animated by sense' is to affirm that it is a merely dependent moment of a larger whole in which it is bound up with certain other moments which can be described abstractly as having the nature of acts or act parts. The dependence is in this case reciprocal: a concrete phenomenon of language use is not a mere heap or sum of separate parts. Rather, the utterance as animated and the animating act components are each such as to exist only as bound up with the other in the framework of a single whole. Hence there can be no question of a chunk of language as it were sitting around waiting to be animated by acts in this way or that, along the lines suggested by Dummett. Act moments and language moments are rather such as to constitute a single entity: they are for example triggered by identical external events, they rest on identical underlying dispositions, and an identical developmental story is to be told in relation to each. The act moments do however at least in this sense have the upper hand, that it is through them that consciousness is channelled, and therefore also connection to our other acts and to external reality.

These act moments are, now, in every case objectifying in the sense set out above. Recall that the immanent content of an objectifying act is that dependent part of the act in virtue of which it

9. Husserl himself was less than fully clear as to the consequences of admitting hybrid structures of this sort. It was left to his student Reinach to draw these consequences in the theory of speech acts he expounded in his "The A Priori Foundations of Civil Law" of 1913. See my "Materials Towards a History of Speech Act Theory", in A. Eschbach, ed., Karl Bühler's Theory of Language, Amsterdam: John Benjamins (1987), 125-52. 
is directed towards this or that object ('object', here, signifying strictly that which is given in experience). The meaning of 'white', for example, is that species to which belong acts which are directed toward the quality white (as a quality given in experience). Not every such act belongs to the species which is the relevant meaning however. The acts instantiating this species are rather only those which are structured by a corresponding and complementary language-component in the way just indicated. Each linguistic meaning is accordingly a special sort of dependent species, in the sense that any instantiating act must stand in the correct sort of reciprocal dependence relation with the language which articulates it. If, for present purposes, we can be allowed to take Frege's theory of unsaturatedness purely in its mereological aspect, then it is as if Husserl has generalised and refined this theory in such a way as to allow not merely one-sided but also mutual unsaturatedness, and in such a way as to allow the domain of unsaturatedness relations to embrace termini drawn from a much wider range. Above all, Husserl goes beyond Frege in allowing entities of one sort to be saturated by entities of other, quite different sorts, as for example when animating acts are saturated by the linguistic components which articulate them (so that we might refer here to something like a transcategorial saturation).

If all of this is well taken, however, and if it is remembered that animating acts are in every case objectifying, then it is difficult to make sense of Dummett's strange claim to the effect that Husserl ought to have had as systematic a theory of the connection between meaning and objectual reference ... as Frege's theory of Sinn and Bedeutung: yet, for all the protracted discussion of meaning in which he engages, he lacked any such theory. This $\ldots$ is the first fundamental difference between him and Frege (p. 50). 
It is difficult, also, to make sense of Dummett's reference to what he sees as

Husserl's failure to explain in what, in general, the meaning of a word consists, or how the meanings of the words go to make up the meaning of the sentence. (p. 46)

Or of Dummett's claim that Husserl

pays little attention ... to the question that Frege was so exercised to answer correctly, what the objectual correlates of expressions of various categories other than that of singular terms should be taken to be. (p. 46)

For the entire Husserlian theory of the objectifying character of acts which are structured by language yields a general explication of just the sort which Dummett finds absent from his works.

Dummett is, certainly, correct to point out that, in regard to expressions in categories other than that of singular terms, a justification is needed why they have not only sense but also reference. We have seen that Frege's theory provides precisely such a justification. Dummett argues that Husserl, in contrast, 'was not troubled by this problem.' (p. 44) If, however, as Husserl tells us, meanings are species of objectifying acts, then in regard to everything that has meaning, i.e. to every meaningful use of language, this implies that we must look for a corresponding objectifying act which, when taken in specie, supplies the relevant meaning in the given context. We shall examine later the detailed consequences of this account of meaning for our understanding of the reference of sentence-using acts. Already at this stage however it is understandable why

Husserl is at one with Frege in regarding all meaningful expressions as having, or at least purporting to have, objectual reference (gegenständliche Beziehung). Indeed, that is the whole point of his using the curious term 'Gegenständlichkeit', which Findlay translates as 'objective correlate' ...: Husserl 
explains that he uses the term because reference is not always to an object properly so called. As much as Frege did, Husserl took for granted that meaningful expressions generally, and not only singular terms, have reference. (pp. 44)

Just as acts and act parts can be divided into dependent and independent (the former being able to exist only in the context of the latter), so the corresponding meanings are divided into syncategorematic and categorematic (and the various possible combinations thereof which arise through concatenation). ${ }^{10}$ And because acts and language here constitute one single concrete phenomenon, the part-whole and dependence relations on the side of the acts will be mirrored in similar relations among the corresponding units of language. It is this which makes it possible for us to express complex meanings by means of sentences.

But what of reference? To answer this question we must begin by considering an act of judgment or assertion. The objectual correlate of such an act is a Sachverhalt or state of affairs, which on Husserl's view is something that is external to the mind yet reflects the structure of the sentence-using act in the sense that it is put together out of parts in a way which reflects the structure of this act and thereby also of the corresponding sentence. It is in this context that Husserl comes closest to provide an equivalent of Frege's account of the way in which the reference of a sentence-whole is related systematically to the reference of the sentence-parts.

We can come to an understanding of what Sachverhalte are by examining Husserl's treatment of specific examples and by attending to the role the concept plays in his wider formal ontology. For our purposes however it is sufficient to note that the Sachverhalt is a certain sort of complex whole which is correlated with a veridical

10. The power of Husserl's analysis of the different possibilities here is shown in the fact that it inspired Lesniewski (and following him Ajdukiewicz) to work out that formal approach to the analysis of language which we now call 'categorial grammar'. 
sentence-using act and is such as to manifest an integrity of its own while at the same time embracing inter alia the objectual-correlates of the successively unfolding sentence parts.

We can now see how, on Husserl's view, it is determined what are the objectual correlates of expressions of the various sorts of subsentential categories. It is useful in this connection to consider the state of affairs as something that comes to be knitted together out of its various parts by the act of assertion. We must then ask what would be the successive constituents of the assertion contribute to constituting a whole of the given sort. For as the reference of a sentence-constituent is for Frege determined by the contribution made by this constituent to determining the truth-value of the sentence as a whole, so for Husserl this reference is determined by the contribution made by the given constituent to determining the integrity of the corresponding Sachverhalt. Consider, for example, prepositions such as 'in', 'on', 'above', 'beside'. Inspection of how the corresponding Sachverhalte are built up, shows that expressions of these sorts have as their objectual correlates certain sorts of relations. The preposition on, for example, has as its objectual correlate a certain real relation, which is to say an entity standing in a pair of one-sided dependence relations to real objects falling within material categories of certain restricted sorts. The logical particle 'and' has as its objectual correlate a relation obtaining not between real objects but between Sachverhalte. Its objectual correlate is, if you like, a doubly unsaturated Sachverhalt, i.e. an entity standing in need of completion by a pair of further Sachverhalte.

Dummett reveals his failure to grasp the Husserlian project when he charges that Husserl 'did not even care very much what we take the objectual correlate of an expression to be, as long as we acknowledge that it has one.' (p. 47) His justification of this peculiar claim turns on an analysis of the following passage drawn, again, from the first Logical Investigation: 
If we consider, e.g., statements of the form ' $\mathrm{S}$ is p', the subject of the statement is generally regarded as the object about which the statement is made. Another view is however possible, which treats the whole state of affairs which corresponds to the statement as an analogue of the object a name names, and distinguishes this from the statement's meaning. (p. 288, translation amended)

Husserl, Dummett tells us, 'does not choose between these options ... and appears indifferent which of them is preferred.' (p. 48) What Husserl actually says, however, is that 'each has its own claims'. And what he means is that, as we have already seen, a complete account of the object-directedness of objectifying acts in general and of acts of assertion in particular must recognise that they may enjoy such directedness to 'Gegenständlichkeiten' on a succession of different levels. Dummett's complaint, then, is rather like the complaint of one who would argue that Frege is indifferent as to what we should regard as the function-argument structure of a sentence because Frege had seen that even the simplest sentence allows us to draw the line between function and argument in a variety of different ways.

This is not, however, to suggest that Husserl's first theory of meaning is without its flaws. Much of the formal machinery that would be needed to make the theory work is barely hinted at in Husserl's text (though it is remarkable how fruitful the hints he supplies turn out to be when one begins to flesh them out in systematic ways). There is however one problem in relation to which the species theory of meaning might seem to face insuperable difficulties: the problem of indexical expressions. Certainly Husserl's theory cannot cope straightforwardly with the meanings of such expressions as the species of the relevant animating acts. For if meaning is always a matter of certain sorts of species, then it is in this sense also always general, where the meanings associated with 
indexical uses of language must surely in some sense participate in the individuality of the corresponding referents.

In the account of perceptual judgment sketched in the sixth Investigation, Husserl does however suggest a way round this problem. ${ }^{11}$ Suppose I look up into the sky and say, 'That blackbird is flying high.' What is the objectifying act which gives meaning to this utterance? Not the perceptual act, for this may vary constantly in such a way as to exhibit continuous qualitative differences which are irrelevant to the meaning of the given statement. The perceptual act has the wrong kind of articulation for the purposes in hand. It can even vanish altogether and my statement will still be meaningful. Husserl argues, therefore that the objectifying act involved here must be an act of a different kind, an act which is not affected by changes of these sorts. ${ }^{12}$ This act is similar in form to an act of judgment. But it manifests an important difference when compared to judgments of the more usual (non-indexical) sort. For where the latter are, when taken in specie, sufficient of themselves to supply a full meaning for the corresponding sentence, the act under consideration here is in this respect incomplete. It has, as it were, the mere torso of a meaning and depends upon the perceptual act to supply, as Husserl puts it in his customary Aristotelian language, 'determinateness of objective reference, and thereby its lowest difference.' (p. 683) Once again, Husserl is working with a theory of integrity of structure whose range of application is wider than that of Frege's theory of unsaturatedness:

11. See $\S \S 4-5$ and compare also Dummett's discussion on p. 94.

12. Here again Dummett reveals his misunderstanding of the Husserlian project when he charges that, according to Husserl, this act of judgment would be 'united' with the act of perception 'in a sense which [Husserl] does not clearly explain.' (p. 95) For Husserl in fact goes into some detail as to the precise nature of the dependence relation that is here involved, employing once again just that theory of parts and unity and of the hierarchical structure of species and genera that he had utilised at every stage in the development of his theory of language and meaning in the Logical Investigations. 
thus he allows that the linguistic act that is here incomplete as far as meaning is concerned may come to be saturated or made complete by acts of other sorts, in this case by acts of perception.

\section{Husserl's Second Theory of Meaning}

It is above all as a result of concentrating his attentions rather narrowly on the interpretation of Husserl's thinking that derives from Dagfinn F $\phi$ llesdal's work that Dummett has failed to appreciate the force of the arguments set forward by Husserl in his earlier theory. For F $\phi$ llesdal's interpretation, which has been elaborated by Woodruff Smith and others, concentrates overwhelmingly on the later doctrine of the 'noema' outlined by Husserl in the first book of the Ideas.

Husserl was responsible, with Frege, for banishing thoughts from the mind. We have seen however, that, in contrast to Frege, he was in his earlier theory able to arrive at a non-psychologistic conception of thoughts which preserves the natural tie (instantiation - a tighter relation than which one cannot hope to find) between thoughts and cognitive activities. The problem of providing a 'linkage' between the two does not, therefore, arise. But what of Husserl's later theory, the theory of noemata? On the interpretation of Husserl defended by F $\phi$ llesdal, the noema is best understood as something like the Fregean sense 'generalised to the sphere of all acts'. ${ }^{13}$ The Fregean sense consists, as we have seen, in the way the reference of the expression is determined, and this is for Frege in every case a step in the determination of the truth-value of a sentence in which this expression occurs. A sense thereby stands in the most intimate relation to truth. Dummett himself accordingly sees reason to object to the noema theory, because to acknowledge noemata (senses, meanings) across

13. Husserl himself occasionally employs a phraseology of this sort, and I shall for present purposes assume, with Dummett, that the F $\phi$ llesdal interpretation of Husserl's later doctrine is correct. 
the whole space of acts would be to break the connection between meaning and the sentence and this would bring the conclusion, anathema to Dummett, that the concept of meaning would have to be elucidated independently of the concept of truth. A more serious objection to the theory, however, is that, with the conception of intentionality in terms of noemata, the linkage problem once more raises its head. For now meanings (i.e. noemata) are seen as intermediaries, falling (somehow) between the act and its (putative) object. The noema theory seems thereby (like Brentano's immanentism) to threaten us with a slide into idealism. For if it is the noema that is responsible for the intentionality of the act, and if, as Husserl supposes, it is possible that every act should have its corresponding noema even in the absence of any external object, then the sceptical question must arise as to what justice we have in presupposing that there are external objects at all. ${ }^{14}$

Husserl's vertical theory is in contrast not subject to this objection, since as we saw, linguistic acts are in every case built up on the basis of the low-grade intentionality of sensory acts, and the latter are guaranteed objectual correlates. Recall the Fregean principle formulated above to the effect that wherever there is sense or meaning there is also a directedness to objects, and wherever there is directedness towards objects there is also sense or meaning. The early Husserl, we can now see, accepted only the first half of this principle, and he thereby staves off the slide into idealism.

\section{What is Analytic Philosophy?}

Dummett is someone who rejects all 'ontological mythology'. Hence unlike Frege he finds it necessary to anchor sense, somehow, in the

14. Cf. Dummett, pp. 55ff. As Russell saw, a similar problem arises when one accepts Frege's distinction between sense and reference. 
world of what happens and is the case. A sense or concept is, he holds (I am here simplifying somewhat), a capacity or disposition. Possession of a concept is an ability. (p. 122) An account along these lines has a number of evident advantages. If senses or concepts are dispositional powers, then clearly they cannot be said to enter into consciousness, they cannot be interpreted as elements of conscious contents. The dispositional account solves at least part of the problem of linkage, for to have a thought is just to activate, in an appropriate way, the relevant constituent capacities. A question, though, is how this account can guarantee the objectivity of thoughts (and for example of scientific theories as complex systems of thoughts). Yet Dummett is not here open to the charge which he himself seems to make against Davidson (p. 147), of having substituted a psychologism of mental capacities for the psychologism of mental episodes. For Dummett insists that the capacities to which he adverts are only partly mental. They are bound up essentially with our capacities of using language. It is this which explains their essential communicability, since the exercise of capacities of the given sort are subject to public observation and control. Through language thoughts can be objective, for language is a social phenomenon.

Dummett sometimes seems to go so far as to identify our capacity to have thoughts with our capacity to use language. Certainly however he holds that the former can be explained only by consideration of the latter. One main thesis of Ursprünge der analytischen Philosophie is in fact that the way to the analysis of thoughts (meanings, concepts) must always proceed though the analysis of language:

even if the subject be supposed to possess the concept before he learns the word, we cannot make use of this hypothesis in explaining in what his understanding of the word consists. ( $p$. 119) 
It is something called the 'public language' which we must take as primary, Dummett holds, not any sort of private accompaniments located in the minds of speakers and hearers.

This main thesis has however been challenged in recent times, and as Frege stands to Husserl, so Dummett himself stands to the 'philosophy of thought' that has been most recently defended in the writings of Gareth Evans. Frege himself called this part of philosophy 'logic'. It concerns itself with the problem what it means to have a thought, as well as with the structure of thoughts and of their constituents. As Dummett argues, while interest in such problems is old,

the philosophy of thought could not emerge as a distinguishable sector until disentangled from the general philosophy of mind. This could happen only after the step had been taken of extruding thoughts from the mind (p. 113).

A programme of the sort defended by Evans, however, which puts analysis of thoughts before analysis of language, brings, in Dummett's eyes, the danger of falling back into psychologism. For if it is not through their linguistic expressions that thoughts are to be analysed, then it seems that one must turn instead to private accompaniments, and this is to put at risk the thesis of communicability.

Husserl, however, as we saw, sees communicability, in the sense of a qualitative and structural similarity of acts of different subjects, as a necessary presupposition of the fact that language should have arisen at all, and a similar idea is of course present also in Aristotle, Descartes, Reid, Fodor, and many others. Dummett's arguments seem in this respect to be open to the charge of putting the epistemological cart before the ontological horse. For even if it is a fact that we can in practice come to know about the putative pre-linguistic structures of thought only through examining how thoughts come to expression in language, it clearly does not follow from this that there are no such 
pre-linguistic structures, that all structure that pertains to thoughts is such as to be acquired only through the machinery of language.

Dummett goes further, however, in claiming that it is the conviction that a philosophical elucidation of thought is to be arrived at through a philosophical analysis of language which distinguishes 'analytic' philosophy from philosophies of other sorts. A claim of this sort has, initially, an air of triviality. Who can deny that the analytic philosophy of subject $\mathrm{X}$ is a philosophy that rests essentially on an analysis of the language we use to talk about X? On closer inspection however Dummett's criterion of what is to count as analytic philosophy yields somewhat surprising implications. Thus as Dummett himself admits, it implies that Evans 'was no longer an analytic philosopher.' (p. 11) And the same applies for example to Russell, to Moore, and also to Chisholm, a philosopher who has argued forcefully in favour of the primacy of the intentional and against that sort of primacy of the linguistic that is defended by Dummett and his allies.

Dummett does certainly help us to understand why it was that language came to play so important a role in philosophy at just the time it did: once thoughts have been banished from consciousness, then one must look elsewhere - 'somewhere non-mythological' ( $p$. 36) - where these thoughts could be contained, and where they could be grasped, affirmed and denied. What better, for this purpose, than the institution of a common language? But do Dummett's discussions really show more than how it came about that the analysis of language came to offer a new and valuable tool for philosophers?

Moreover, even if Dummett's criterion were to be found acceptable, then it seems clear that more would be needed, in fixing the nature of analytic philosophy, than a thesis as to the relations of priority as between analysis of language and analysis of thought. For something needs to be said also as to the nature of the sorts of 'analysis' that one will accept. It would, for example, be to go too far 
to admit only logical analyses, or analyses employing only concepts recursively defined. For then it would turn out that someone like the later Wittgenstein could no longer be counted as a philosopher of the analytic sort. On the other hand we do not need to look very far to see that not every sort of 'analysis of language' is here admissible.

When we look more carefully at the characteristic achievements of analytic philosophy, however, then we see that these were arrived at not by any mere analysis of language, but via a whole panoply of logical and extra-logical procedures, ranging from the exploitation of new insights of a broadly sociological sort into the way a language works (and is intervolved with other sorts of human institution, including other languages and idiolects), to insights into the shortcomings of e.g. certain sorts of reductionist theories deriving from arguments demonstrating that the theories in question are incompatible with central features of our common-sense view of reality. Even Frege's idea of how to analyse a sentence was itself derived not from analysis of language but from reflection (one might almost say ontological reflection) on the nature of the function in mathematics.

If, however, one is forced to choose some single most conspicuous feature that runs though the whole history of analytic philosophy and sets it apart from philosophies of other sorts, then it would seem that it is the form or style of this philosophy which offers itself as the most serviceable candidate. Analytic philosophy is, somewhat crudely put, exact philosophy, in the sense that it strives for clear and careful formulation in ways involving inter alia the analysis of language (the latter understood broadly enough to include also a sensitivity to the potential pitfalls that are involved in any use of language for philosophical purposes). It is this which makes possible argument in philosophy, and even refutation. Frege's formulations were for the first time so rigorous and precise, that one could see where they were wrong and argue decisively against them. 